\title{
EFFICACY OF LOW DOSE LOW MOLECULAR WEIGHT HEPARIN IN THE TREATMENT OF CUTANEOUS LICHEN PLANUS.
}

\author{
Khan MSI ${ }^{1}$, Uddin $\mathrm{MN}^{2}$, Shah MOR ${ }^{3}$, Khondker L ${ }^{4}$, Hasan $\mathrm{MS}^{5}$
}

\begin{abstract}
Introduction: Lichen planus is a common pruritic, inflammatory disease of the skin, mucous membranes, nail and hair follicles. Low dose low molecular weight heparin is administered in the treatment of cutaneous lichen planus.
\end{abstract}

Objective: The objective is to evaluate the efficacy of low dose low molecular weight heparin in the treatment of cutaneous lichen planus.

Materials and Methods: An interventional study was carried out in the department of Dermatology and Venereology, Combined Military Hospital $(\mathrm{CMH})$, Dhaka. Total thirty seven patients of cutaneous lichen planus were selected by purposive type non-probability sampling technique. Data were collected by face to face interview and clinical examination.

Results: It was observed that before treatment, the score of cutaneous lichen planus lesion was 6.83 \pm 1.30 and after treatment was $3.83 \pm 1.18$ and ' $t$ ' test was found statistically significant $(\mathrm{P}<0.05)$. Improvement was shown in $26(70.27 \%)$ cases. Out of these, response was good in $23(88.46 \%)$, fair in $2(7.69 \%)$ and poor in $1(3.85 \%)$ cases.

Conclusion: The study revealed that low dose low molecular weight heparin has remarkable efficacy profile as treatment option for cutaneous lichen planus.
Key-Words: Cutaneous lichen planus, efficacy of low molecular weight heparin.

\section{Introduction}

Lichen planus is an inflammatory mucocutaneous condition. It typically persists for 1 to 2 years, may follow a chronic relapsing course over many years ${ }^{1,2}$. The prevalence of lichen planus is $<1 \%$ (0.14-0.80\%) worldwide ${ }^{3,4,5}$. Relapse of disease occurs in 15 percent to 20 percent of cases and tends to occur in the same area as the initial episode ${ }^{6}$. The primary lesions of lichen planus are characteristic, almost pathognomonic, small, violaceous, flat-topped, polygonal papule. On the surface gray or white puncta or streaks (Wickham striae) cross the lesions. Koebner phenomenon occurs in lichen planus. Pruritus is often prominent in lichen planus ${ }^{7,8}$. There is a predilection for the flexor wrists, trunk, medial thighs, shins, dorsal hands and glans penis. Nail changes are present in approximately $5-10 \%$ and pterygium formation is characteristic $^{1,9}$. Lichen planus may be a cause of twenty nail dystrophy. Association of lichen planus with syphilis, Herpes Simplex Virus-2 (HSV-2), Human Immunodeficiency Virus (HIV), amoebiasis, chronic bladder infection, hepatitis C, Helicobacter pylori or Human Papilloma Virus (HPV) have been reported ${ }^{10}$.

1. Lt Col Md Shirajul Islam Khan, MBBS, DDV, MCPS (Dermatology and Venereology), Graded Spl in Dermatology and Venereology, AFMI, Dhaka Cantt. 2. Maj Gen Md Nasir Uddin, MBBS, MPH, MPhil (PSM), Commandant, AFMC, Dhaka Cantt. 3. Col Md Obaidur Rahman Shah, MBBS, DDV, FCPS (Dermatology and Venereology), Former Classified Specialist in Dermatology and Venereology, CMH, Dhaka Cantt. 4. Dr. Lubna Khondker, MBBS, MPH, DDV, MCPS, FCPS (Dermatology and Venereology), Asst Prof of Dermatology and Venereology, BSMMU, Dhaka. 5. Lt Col Md Sayeed Hasan, MBBS, DDV, FCPS (Dermatology and Venereology), Asst Prof of Dermatology and Venereology, AFMC, Dhaka Cantt. 
Low molecular weight heparin in low doses has lymphoid antiproliferative and immunomodulatory properties ${ }^{11}$. Evidence suggests that lichen planus is a T-cell mediated skin disorder. The dermal infiltrate consists largely of T-cells that attach to keratinocytes. This lymphocyte-keratinocyte apposition is believed to lead to the destruction of the epidermis. Administration of low dose low molecular weight heparin (devoid of anticoagulant activity) inhibits T-lymphocyte heparanase activity, which is crucial in $\mathrm{T}$ cell migration to target tissues in lichen planus ${ }^{12}$. In Bangladesh, low molecular weight heparin has recently been used to treat lichen planus. Unfortunately there are few studies taken regarding this drug over Bangladeshi people. The present study was designed to assess the effectiveness of low dose low molecular weight heparin in the treatment of cutaneous lichen planus.

\section{Materials and Methods}

An interventional study was carried out for a period from July 2009 to June 2010, in the department of Dermatology and Venereology, Combined Military Hospital (CMH), Dhaka. Purposive type non-probability sampling technique was followed in this study. Data were collected from the patients by face to face interview and also from clinical records. Questionnaire was developed for collection of relevant information. Patients suffering from lichen planus were selected as study population. During the data collection period, 37 patients of cutaneous lichen planus were assigned purposively, considering inclusion and exclusion criteria for patient selection.

\section{Inclusion criteria}

1. Both male and female patients of 20 to 50 years of age.

2. Patients suffering from cutaneous lichen planus only.

3. Patients willing to give consent to take part in the study.

4. Patients expected to be available for the duration of study.

5. Patients should be clinically and histopathologically diagnosed.

\section{Exclusion criteria}

1. Patients with known hypersensitivity to any of the ingredients of the study medication.

2. Patients suffering from drug induced lichen planus

3. Patients suffering from mucosal or oral lichen planus.

4. Patients having systemic therapy for lichen planus within one month prior to the study.

5. Patients having topical therapy within 2 weeks prior to the study.

At first the patients of cutaneous lichen planus were identified. Then clinical conditions of the patients were recorded and skin biopsies were done for histopathological examination. After that verbal and written consent were taken from the selected patients; they were interviewed by asking questions. Present clinical conditions were recorded, along with follow up in subsequent visits of selected patients. The questionnaire included selected parameters related to clinical characteristics, the grading of complaints, the clinical findings before and after treatment and the level of improvement after application of drug. After collection, all the data were cleaned by checking consistency and then were edited and analyzed by software SPSS-12.0 (Statistical Package for Social Science) and were presented according to objectives and variables of the study.

Procedure of Treatment: All patients of cutaneous lichen planus were treated with $3 \mathrm{mg} / \mathrm{ml}$ low molecular weight heparin (enoxaparin), subcutaneously once in a week for duration of 6 weeks. Additional therapies were restricted. First follow-up was done after 4 weeks and second follow up was done after 8 weeks of administration of last dose of medication.

Clinical Assessment: Skin involvement before and after therapy was assessed by a clinical score. Briefly the method consists of determination of different grades of papules, scaly lesions and pigmentation: $0=$ normal, $1=$ mild, $2=$ moderate and $3=$ severe for all. Total clinical score of each single patient was determined by addition of the 
scores. Response study was recorded as: Excellent $>75 \%$ improvement, Good $50-75 \%$ clearing, Fair $25-50 \%$ clearing and Poor $<25 \%$ clearing.

\section{Results}

This study is an interventional type of study, conducted on thirty-seven patients with a view to assess the efficacy of low dose low molecular weight heparin for the treatment of cutaneous lichen planus.

Table-I shows that the mean age of the patients was $36 \pm 6.6$ years and their age ranged from 20 to 50 years. Among the 37 patients, highest percentage of patients, $21(56.8 \%)$ were in between the 30 to 40 years of age, followed by 10 $(27 \%)$ who were 40 to 50 years of age and 6 $(16.2 \%)$ were in between 20 to 30 years of age.

Table-I: Distribution of the patients according to age $(n=37)$

$\begin{array}{ccc}\text { Age(in years) } & \text { Frequency } & \text { Percentage } \\ 20-30 & 6 & 16.2 \\ 30-40 & 21 & 56.8 \\ 40-50 & 10 & 27.0 \\ \text { Total } & \mathbf{3 7} & \mathbf{1 0 0 . 0}\end{array}$

Table-II shows that before treatment, 19(51.4\%) cases had moderate, $16(43.2 \%)$ cases had severe and $2(5.4 \%)$ cases had mild type of papular eruption. After treatment, 16(43.2\%) had mild, 11(29.7\%) had severe type and $10(27 \%)$ cases had no papular eruption at all. Before treatment, scaly lesion was severe in $10(27 \%)$ cases, moderate in $20(54.1 \%)$ cases and mild type in $7(18.9 \%)$ cases. After treatment, 7(18.9\%) had no lesion, 19(51.4\%) had mild, $7(18.9 \%)$ had moderate and Only $4(10.8 \%)$ patients had severe type of scaly lesion. It was found that before treatment, $14(37.8 \%)$ cases had severe and $23(62.2 \%)$ cases had moderate type of skin pigmentation. But after treatment, 9(24.3\%) had no pigmentation, $17(45.9 \%)$ had mild, $4(10.8 \%)$ had moderate and only $7(18.9 \%)$ patients had severe type of pigmentation.
Table-II: Distribution of patients by grading of clinical findings before and after treatment.

$\begin{array}{llll}\text { Clinical findings } & & \begin{array}{l}\text { Before } \\ \text { treatment }\end{array} & \begin{array}{l}\text { After } \\ \text { treatment }\end{array} \\ \text { Papular eruption } & \text { Normal } & 0(00) & 10(27) \\ & \text { Mild } & 2(5.4) & 16(43.2) \\ & \text { Moderate } & 19(51.4) & 0(00)\end{array}$

Table-III shows distribution of score of patients before treatment and after treatment. It was observed that score of patients of lichen planus, before treatment was $6.83 \pm 1.30$ and after treatment was $3.83 \pm 1.18$. ' $t$ ' test was done and found statistically significant $(\mathrm{P}<0.05)$.

Table-III: Mean distribution of score of patients before and after treatment $(n=37)$.

\section{Treatment Mean \pm SD t-value $p$-value \\ Before treatment $6.83 \pm 1.30$ \\ After treatment $\quad 3.83 \pm 1.18 \quad 4.967 \quad 0.001(<0.05)$}

Fig-1 shows level of improvement, among patients of cutaneous lichen planus. Improvement was seen in $26(70.27 \%)$ cases and $11(29.73 \%)$ cases showed no improvement at all. 


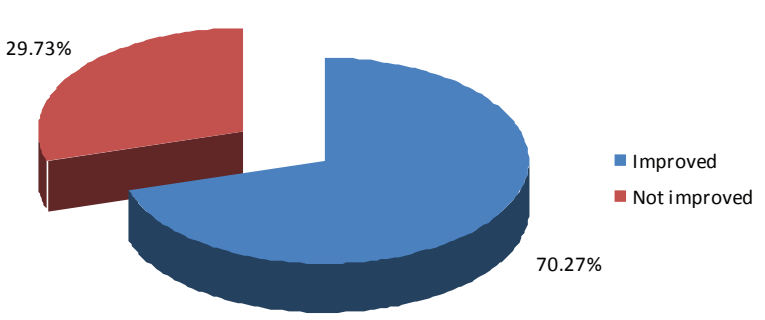

Fig-1 Distribution of patients by level of improvement.

In Table-IV, level of improvement was observed on the 1st follow up visit at the end of 4 weeks. Response was fair in $10(38.46 \%)$ cases and poor in $16(61.54 \%)$ cases. Marked improvement observed on the 2nd follow up visit at the end of 8 weeks. Response was good in $23(88.46 \%)$ cases, fair in $2(7.69 \%)$ cases and poor in $1(3.85 \%)$ cases. Statistical test was done and found significant $(\mathrm{p}<05)$.

Table-IV: Distribution of response of treatment at different weeks $(n=37)$.

\begin{tabular}{|l|c|c|}
\hline Response & $\begin{array}{c}\mathbf{4} \text { weeks of } \\
\text { treatment }\end{array}$ & $\mathbf{8}$ weeks of treatment \\
\hline Excellent & 0 & 0 \\
\hline Good & 0 & $23(88.46 \%)$ \\
\hline Fair & $10(38.46 \%)$ & $2(7.69 \%)$ \\
\hline Poor & $16(61.54 \%)$ & $1(3.85 \%)$ \\
\hline
\end{tabular}

$p=0.016(<0.05), p$-value reached from unpaired t-test.

It was seen in the study that $29(78.4 \%)$ patients had no side effects and $8(21.6 \%)$ had side effects of drug, shown in Fig-2. Among the patients having side effects, $5(62.50 \%)$ suffered from local irritation, 2(25.0\%) from bruises and 1(12.5\%) patient suffered from headache, shown in Fig-3.

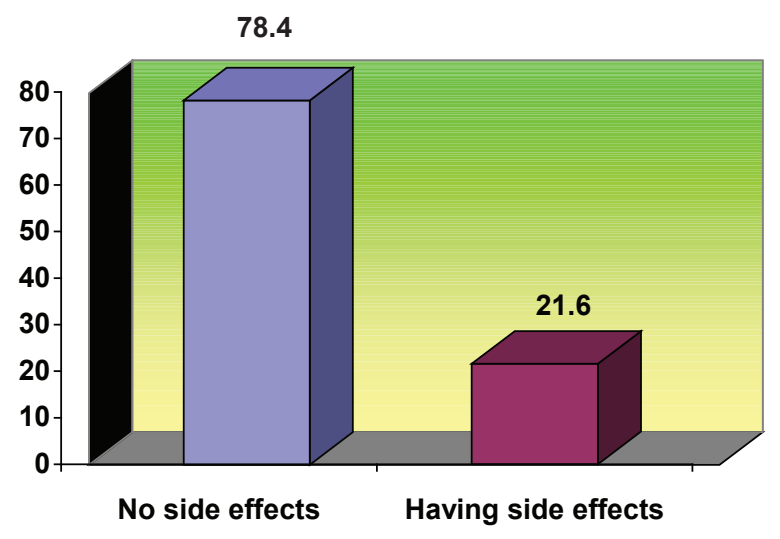

Fig-2: Distribution of patients based on the side effects.

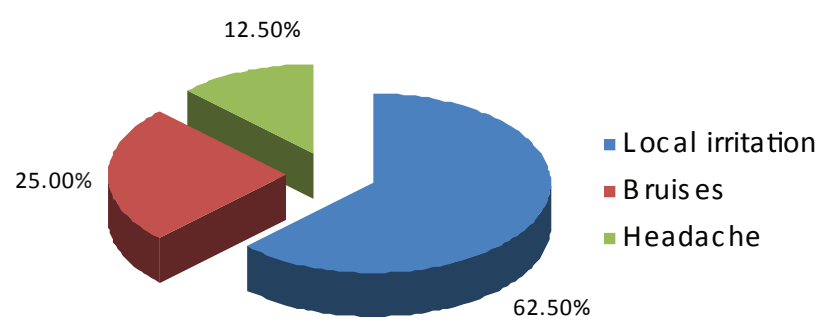

Fig-3: Distribution of patients according to the side effects of various natures.

\section{Discussion}

A total of thirty seven patients were studied. The mean age of the patients was $36 \pm 6.6$ years and their age ranged from 20 to 50 years. Among the patients, highest percentage of patients, 21(56.8\%) were in between 30 to 40 years of age, followed by $10(27 \%)$ were 40 to 50 years old and $6(16.2 \%)$ were in between the 20-30 years of age, similar to the study finding of Kanwar et al and Jingling et al ${ }^{13,14}$.

In our study, improvement was shown in 26 (70.27\%) cases and 11(29.73\%) cases showed no improvement at all. Statistical test was done and found significant $(\mathrm{p}<05)$. Complete remission was observed in $20(83 \%)$ patients among 24 patients of lichen planus in the study of Akdeniz et al ${ }^{15}$. The similar type of finding was also observed in study of Hodak et al in Department of Dermatology, Hadassah Medical Center, Jerusalem, Israel, 
where ten histologically defined lichen planus patients were treated and out of ten patients, eight patients showed complete regression of eruption with residual post-inflammatory hyperpigmentation and in one patient marked improvement was seen ${ }^{16}$. A study by Pacheco et al observed that five among seven patients of cutaneous lichen planus experienced a marked improvement, when treated with low-molecular weight heparin ${ }^{17}$.

Level of improvement was observed on the 1st follow up visit at the end of 4 weeks. Response was fair in $10(38.46 \%)$ cases and poor in 16 $(61.54 \%)$ cases. Marked improvement was observed on the 2nd follow up visit at the end of 8 weeks. Response was good in $23(88.46 \%)$ cases, fair in $2(7.69 \%)$ and poor in $1(3.85 \%)$ case. Similar finding was observed by Hodak et al where within 4 to 10 weeks, complete regression of eruption with residual post-inflammatory hyperpigmentation was seen in eight patients and marked improvement was found in one patient ${ }^{16}$.

It was seen that $29(78.4 \%)$ had no side effect and $8(21.6 \%)$ had side effects of drugs, not similar to the study finding of Akdeniz et al, where twenty four patients were treated by low molecular weight heparin and complete remission was observed without any side effect ${ }^{15}$. Similar study finding was also observed by Pacheco et al when seven patients of cutaneous lichen planus were treated with low-molecular weight heparin where marked improvement was seen without any side effect ${ }^{17}$.

\section{Conclusion}

The study revealed that improvement was good in three-fourth cases. So, it can be concluded that low dose low molecular weight heparin has remarkable efficacy profile as treatment option for cutaneous lichen planus. As low molecular weight heparin is still expensive, further studies to evaluate costeffectiveness may be performed. This was an open and uncontrolled study on a limited number of cases. Further blinded, randomized, placebo-controlled studies are needed to investigate the effectiveness of therapy.

\section{References}

1.James WD, Berger TG, Elston DM. Andrew's Disease of the skin-Clinical Dermatology. 10th edition. USA: Saunders Elsevier; 2006. 217-25.

2.Pittelkow MR., Dauod MS. Lichen Planus. Wolff K, Goldsmith LA, Katz SI, Gilchrest BA, Paller AS and Leffell DJ. Fitzpatrick's Dermatology in General Medicine. New York: The McGraw- Hill Companies; 2008. 244-55.

3.Stefanidou MP, Ioannidou DJ, Panayiotides JG, Tosca AD. Low dose molecular weight heparin: a novel alternative therapeutic approach for lichen planus. Br J Dermatol 1999; 141(6): 1040-5.

4.Rai R, Kaur I, Kumar B. Low dose molecular weight heparin in lichen planus. J Am Acad Dermatol 2002; 46(1): 141-3.

5 Dotan I, Hallak A, Arber N, Santo M, Alexandro A, Knaani Y, Hershkoviz R, Brazowski E and Halpern Z. Low dose molecular weight heparin (enoxaparin) is effective as adjuvant treatment in active ulcerative colitis: An open trial.Journal of Digestive diseases and sciences 2001; 46(10):2239-44.

6. Khondker L, Wahab MA, Khan SA. Profile of lichen planus in Bangladesh. Mymensingh Med J 2010 Apr; 19(2): 250-3.

7. Edith. Lichen planus in African Children: A Study of 13 patients. Padiatric Dermatology. 2007; 24(5): 495-8.

8. Higgins CR, Jones SH, Black MM. Erosive, Flexural lichen planus-an uncommon variant. Clinical and Experimental Dermatology. 2006; 18(2): 169-70.

9. Olaniyi. Evaluation of clinical types of cutaneous lichen planus in anti- hepatitis $C$ virus seronegative and seropositive Nigerian patients. International Journal of Dermatology. 2003; 42(12): 933-5. 
10. Eisen D, Carrozzo M, Sebastian JVB and Thongprasom K. Number V Oral lichen planus: clinical features and management. Oral diseases 2005; 11(6): 338-49.

11. Nagao T, Ikeda N, Fukano H, Hashimoto $\mathrm{S}$, Shimozato K and Warnakulasusiya S. Incidence rates for

oral leukoplakia and lichen planus in a Japanese population. Journal of Oral Pathology and Medicine2005; 34(9): 532-9.

12. Axell $\mathrm{T}$ and Rundquist L. Oral lichen planus- a demographic study. Community Dentistry and Oral

Epidemiology 2006; 15(1): 52-6.

13. Kanwar AJ, Dogra S, Handa S, Parsad D, Radotra BD. A study of 124 Indian patients with lichen

planus pigmentosus. Clinical and Experimental Dermatology. 2003; 28(5): 481-5.
14. Jingling Fan MW, Wang S, Wang SZ, Chen XM, Li Y, Wang L. A clinical study of 674 patients with

oral lichen planus in China. Journal of Oral Pathology and Medicine. 2005; 34(8): 467- 72.

15. Akdeniz S, Harman M, Atmaca S, Yaldiz M. The management of lichen planus with lowmolecular weight heparin (enoxaparin). Int J Clin Pract.2005; 59(11): 1268-71.

16. Hodak E, Yosipovitch G, David M, Ingber A, Chorev L, Lider O, Cahalon L, Cohen IR. Low-

molecular weight heparin (enoxaparin) is beneficial in Lichen Planus: a preliminary report. J Am Acad Dermatol 1998; 38: 564-8.

17. Pacheco H, Kerdel F. Successful treatment of lichen planus with low- molecular weight heparin: a

case series of seven patients. Journal of Dermatological Treatment 2001; 12(2): 123-6. 